\title{
The Enhancement of Pregnant Women's Knowledge and Attitude to Maternal Health through Art of 'Dulmuluk' in Ogan Ilir District, South Sumatera
}

\author{
Rini Mutahar $^{1}$, Arie Kusumaningrum ${ }^{2}$, Diana Dewi Sartika ${ }^{3}$, Wasis Budiarto ${ }^{4}$ \\ ${ }^{1}$ Public Health Faculty, Sriwijaya University, Indonesia

\begin{abstract}
Maternal health still become problem in Indonesia. Indonesia Health Demographic Survey found that postpartum visit in South Sumatera about $\mathbf{7 8 \%}$, exclusive breastfeeding $38 \%$, and Early Latch on $29 \%$, all of them are under national average. Lack of knowledge and mother's attitude about maternal health associated with early detection of health problems during pregnancy, and childbirth. The study objective was to examine the influence of "DulMuluk Traditional Theatre" in increasing knowledge and attitudes of pregnant mothers about maternal health. The study design methodology was quasi-experimental design. The population was all pregnant women in Pemulutan and South Indralaya, Ogan Ilir, South Sumatera. The sample size was 50 pregnant mothers for intervention group and 50 pregnant women in the control group. In control group, the sample did not get the intervention of DulMuluk Theatre while in intervention group, the sample got "DulMuluk Traditional Theatre" that contained maternal health information. Data was analyzed using $t$ test. The result showed that there were no significant differences in age, education, occupation, socioeconomic status and parity in both control and intervention group. Statistically, there was significant difference on the average score of knowledge at before and after the intervention both in the group with DulMuluk Traditional Theatre (p-value 0.0048 ) and increased an average score of attitude (p-value 0,01$)$. The conclusion was that knowledge and attitudes of pregnant women after the intervention of DulMuluk Traditional Theatre that contained health education was increasing. It is suggested that DulMuluk Traditional Theatre could be implemented as an arts that could educate the public by including more health messages in daily life.
\end{abstract}

Keywords - DulMuluk, Traditional Theatre, Knowledge, Attitude, Maternal health.

\section{INTRODUCTION}

Maternal mortality is strongly associated with early detection of health problems during pregnancy and child birth. A problem in improving maternal health is an examination or a visit of the maternity pregnant women to the health personnel. Postpartum care coverage in the first 3 days in South Sumatera was only by $78 \%$ (national $81.9 \%$ ). Exclusive breastfeeding was only $38 \%$. Percentage process of early breastfeeding for children aged 0 23 months was less than one hour after the baby born was $29.6 \%$ (National was 34.5\%). Pregnancy test in Ogan Ilir for first medical examination as many as 11228 of 12369 visits $(87 \%)$. There were $15 \%$ of births are not attended by health workers and postpartum care coverage $84 \%$, a percentage of $81.28 \%$ TT immunization coverage, and mothers who get $\mathrm{Fe} 1$ and $\mathrm{Fe} 3$ is $86 \%$ and $81 \%$ [5].

Ogan Ilir is a rural area and the results of expansion of Ogan Ilir district which was inaugurated in 2004 (Act No.37 of 2003) is composed of 16 districts and mostly as low lands (65\% and swamp land 35\%). One of tradition in Ogan Ilir was local drama called DulMuluk Art. DulMuluk was consisted of poems and advice that represent cultural values that could be applied in daily life. Maternal health poem consists of prenatal care (antenatal care), birth plans, early initiation of breastfeeding, exclusive breastfeeding, immunization and iron tablets. Health intervention by using DulMuluk has two benefits, the first as a vehicle in health promotion and prevention and the second as conserve local culture-based arts which once triumphed. 
Ogan Ilir is a rural area and the results of expansion of Ogan Ilir district which was inaugurated in 2004 (Act No.37 of 2003) is composed of 16 districts and mostly as low lands $(65 \%)$ and swampland (35\%). One of tradition in Ogan Ilir was local drama called DulMuluk Art. DulMuluk was consisted of poems and advice that represent cultural values that could be applied in daily life. Maternal health poem consists of prenatal care (antenatal care), birth plans, early initiation of breastfeeding, exclusive breastfeeding, immunization and iron tablets. Health intervention by using DulMuluk has two benefits, the first as a vehicle in health promotion and prevention and the second as conserve local culture-based arts which once triumphed.

\section{MATERIALS AND METHODS}

The study design was quasi-experimental design. This research was described the strength of relationship between "DulMuluk Art" intervention with regular counseling from the aspect of knowledge and attitudes of pregnant women in Maternal Health. The variable of knowledge and attitudes were numeric data that was measured by increased score for knowledge and attitudes before and after intervention. The research location was in the district of South Inderalaya and Pemulutan District, Ogan Ilir. DulMuluk Art Intervention was given in Pemulutan District while control group was South Inderalaya District. The intervention group was given DulMuluk Theater intervention in pregnant women. The control group was given counseling by health workers.

The population was all pregnant women in the Inderalaya Selatan District and Pemulutan Subdistrict in South Indralaya, Ogan Ilir. The sample was pregnant women in the District of South Indralaya and Pemulutan, Ogan Ilir by using systematic random sampling. Sample s ize was determined by calculation of sample size in different hypotheses test of the average on two independent groups. The formula derived from a large sample of 50 pregnant women in the treatment group and 50 pregnant women in the control group with a total of 100 respondents. Inclusion criteria of research subjects were : (1) The health condition of healthy, not being hospitalized; (2) Available to get participated in the study completion, and the exclusion does not suffer from serious diseases.

Data analysis was performed with univariate and bivariate analysis. Ethic Determination by approval of the Ethics Committee of Research and Development of Health through the Center for the Humanities, Health Policy and Health Empowerment.

\section{RESULT AND DISCUSSION}

The amount of the planned sample of 100 people consisting of 50 pregnant women in the intervention group and 50 pregnant women pregnant in the control group. By the end of the study there were two pregnant women were considered out (drop out) in the control group. With the respondents came out of the study, the number of pregnant women who participated in research until the end of the 98 people, consisting of 50 pregnant women in the intervention group and 48 pregnant women in the control group. The number is still considered eligible minimum sample study.

In presenting these characteristics will be presented a comparison between the characteristics of the respondent with the treatment given teach risk factor. It is to know the characteristics of pregnant women between the intervention and control groups comparable.

The majority of women aged between 18-35 years (86) and as many as 12 people aged less than 18 and more than 35 years. When compared with the intervention given then amounted to $84.4 \%$ (42) as a control group and $91.7 \%$ (44 people) is the intervention group aged 18-35years. Based on statistical test there was no significant difference in maternal age in both intervention groups ( $p>0.05)$. 
TABLE I

DISTRIBUTION OF RESPONDENT CHARACTERISTIC BY INTERVENTION GROUP IN OGAN ILIR 2014

\begin{tabular}{|c|c|c|c|c|c|c|}
\hline \multirow[t]{2}{*}{ Variables } & \multicolumn{2}{|c|}{$\begin{array}{l}\text { Control } \\
\text { Group }\end{array}$} & \multicolumn{2}{|c|}{$\begin{array}{l}\text { Intervention } \\
\text { Group }\end{array}$} & \multirow[t]{2}{*}{ Total } & \multirow[t]{2}{*}{$\begin{array}{c}\mathrm{P} \\
\text { value }\end{array}$} \\
\hline & $\mathrm{n}$ & $\%$ & $\mathrm{n}$ & $\%$ & & \\
\hline \multicolumn{7}{|l|}{ Age } \\
\hline$<18 \&>35$ & 8 & 16.0 & 4 & 8.3 & 12 & 0.247 \\
\hline $18-35$ & 42 & 84.4 & 44 & 91.7 & 86 & \\
\hline \multicolumn{7}{|l|}{ Educational status } \\
\hline $\begin{array}{l}\text { Low (not completed } \\
\text { senior high school) }\end{array}$ & 31 & 62.0 & 32 & 66.7 & 63 & 0.630 \\
\hline $\begin{array}{l}\text { High (completed } \\
\text { senior high school) }\end{array}$ & 19 & 38.0 & 16 & 33.3 & 35 & \\
\hline \multicolumn{7}{|l|}{ Occupational status } \\
\hline Not working & 39 & 78.0 & 45 & 93.8 & 84 & 0.026 \\
\hline Working & 11 & 22.0 & 36 & 6.2 & 14 & \\
\hline $\begin{array}{l}\text { Sosioeconomic } \\
\text { status* }\end{array}$ & - & & & & & \\
\hline$\leq$ Median & 23 & 54.0 & 36 & 75.0 & 59 & 0.03 \\
\hline$\geq$ Median & 27 & 46.0 & 12 & 25.0 & 39 & \\
\hline \multicolumn{7}{|l|}{ Parity status* } \\
\hline Multiparous & 38 & 79.2 & 20 & 71.4 & 58 & 0.444 \\
\hline Primiparous & 10 & 20.8 & 8 & 28.6 & 18 & \\
\hline Total & & & & & 98 & \\
\hline
\end{tabular}

*Socioeconomic status based on median of income variable. The intervention group was Rp1.350.000,00 while the control group Rp1.000.000,00

**The sample was not 98 because the first children did not have parity

This suggests that maternal age in both groups were comparable. These results are also obtained on their maternal characteristics, such as level of education and parity. In both groups, levels of education and parity of pregnant women, both the control and intervention groups are comparable $(p>$ 0.05). The variable of socioeconomic level and employment status show the differences in both group by statistical test $(\mathrm{p}<0.05)$.

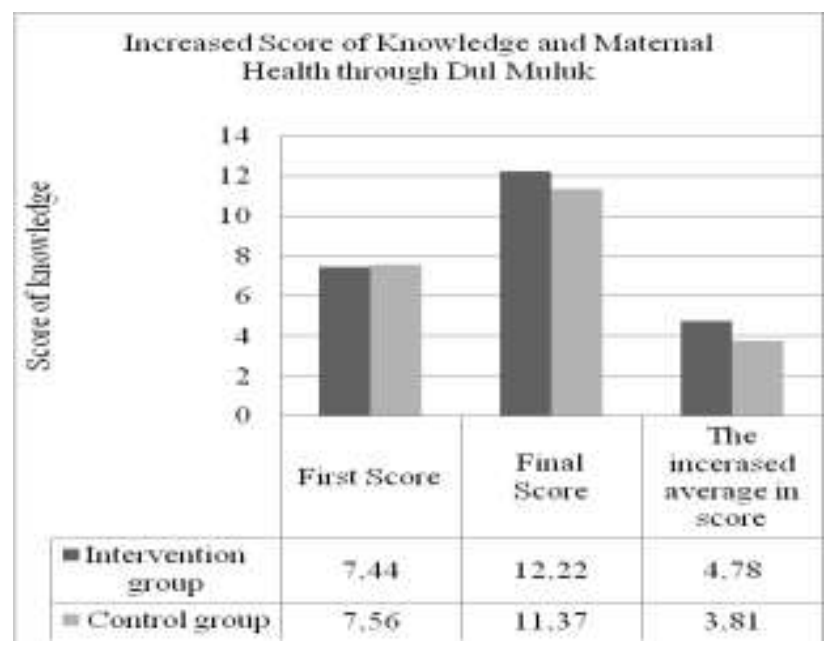

Fig. 1 Increased Score of Knowledge and Maternal Health
The majority of women aged between 18-35 years (86) and as many as 12 people aged less than 18 and more than 35years. When compared with the intervention given then amounted to $84.4 \%$ (42) as a control group and $91.7 \%$ (44 people) is the intervention group aged 18-35 years. Based on statistical test there was no significant difference in maternal age in both intervention groups $(p>0.05)$. This suggests that maternal age in both groups were comparable. These results are also obtained other maternal characteristics, such as level of education and parity. In both groups, levels of education and parity of pregnant women, both the control and intervention groups are comparable ( $p>$ 0.05 ). The variable of socio economic level and employment status show the differences in both group by statistical test $(\mathrm{p}<0.05)$.

Improved score of knowledge and attitude of pregnant women against maternal health through DulMuluk intervention showed that the average score of the initial knowledge of pregnant women in the group given artistic intervention DulMuluk of 7.44 and an average score of knowledge end after the intervention of art DulMuluk given rise to 12.22. While the average knowledge score early in the intervention group were given counseling prior to the intervention amounted to an average of 7.56 and a score of knowledge final after being given counseling intervention increased to 11.37. The average increase in knowledge scores in the group of pregnant women who are given artistic intervention DulMuluk increased by 4.78 and the average increase in knowledge scores in the mother given counseling interventions increased by 3.81 . There was a significant difference in the average scores of knowledge before and after the intervention both in the group treated DulMuluk or given counseling ( $\mathrm{p}$ value $=0.0048$ ).

The average score of the initial attitude of pregnant women in the group given artistic intervention DulMuluk before intervention was at 56.38 and the average score of the attitude of the final after being given artistic intervention DulMuluk increased to 59.44. While the average score of attitude early in the intervention group were given counseling before intervention is at 55.81 and the average score of knowledge final after being given counseling intervention increased 
to 56.58. The average increase in scores on the attitude of a group of pregnant women who were given artistic intervention DulMuluk increased by 3.06 and the average increase in scores on the attitude of the mother given counseling interventions increased by 0.77 . There was a significant difference in the average score of attitude before and after the intervention both in the group treated DulMuluk art and given counseling ( $\mathrm{p}$ $<0.01$ ). Based on statistical test also showed that there were significant differences increase in the average score of attitude among pregnant women given DulMuluk art intervention with pregnant women who are given counseling intervention.

The results showed that there was significant improvement in terms of knowledge and attitude of pregnant women on maternal and child health. It was appropriate. This was because that in DulMuluk perform involves multiple sensory involved. States that in the early stages to identify the learning style learning targets, one step among the first steps that should be performed by a teacher is to identify the modalities of student learning as visual modality, auditory, or kinesthetic, this approach is called a sensory preference approach [4]. Judging from sensory approach to learning style preference, visual learners learn by what they see, auditory learners learn through what they hear, and kinesthetic learners learn through movement and touch. Although each person learns the three modalities, according DePorter \& Hernacki (1999) at a certain stage, most people are more inclined to one among the three. This shows that the process of learners with sensory preferences that involve multiple sensory faster to convey messages and more easily accepted [4].

The intervention in the school drama program effectively improve students' knowledge and attitudes towards HIV/AIDS better than the school group intervened with written information only [7]. Watch the drama after the discussion on the topics shown a significant impact on improving knowledge and attitudes [2].

Same with the previous study in Bali Indonesia. The research found that method of innovative puppet and speech group had significant knowledge and perception improvement of head family in HIV/AIDS prevention. However, innovative Bali puppet media which was better than speech group to improve knowledge and perception about HIV/AIDS prevention [9]. In other place of Bali, there was Cenk Blonk Puppet which use as sexual education media for Hinduism. It was very potential as sexual education media ${ }^{(1)}$. In Banyuwangi East Java there was Memengan Dance as health promotion media to mothers and children at Posyandu (Integrated Health Service Unit) [11].

Red Cross National Societies in countries such as Togo, Zambia, Malawi, and Zimbabwe have integrated theatre and drama into the community social mobilization activities. The shows are incorporated into community-based health education programs to raise awareness about childhood immunizations, malaria prevention, and other health education activities. The theatre performances are followed by question and answer sessions [10].

Based on some previous researches. We can say that local art theatre was effective health promotion media. Theatre able to engage diverse audiences and to arouse their emotions to stimulate acceptance of the messages. Theatre helps to break down barriers that traditional formal health promotion messages cannot [10].

\section{CONCLUSIONS}

Based on the results and discussion in this study it could be concluded:

1. The process of packing the maternal health messages conveyed by DulMuluk obtained with the theme of the study of the material is good, the message delivered well to the target, and the addition of maternal and child health topics tailored to maternal health.

2. Improved knowledge, attitudes and behavior of pregnant women that concluded as follow:

a. There is a significant difference in the average scores of knowledge before and after the intervention DulMuluk (an average of 7.44 to 12.22 , an increase in score of $4.78, \mathrm{p}<0.05)$. There is a significant difference in the average scores of knowledge before and after the intervention counseling (average 7.56 to 11.37, an increase in score of $3.81 \mathrm{p}<0.05$ ).

b. There is a significant difference in the average score of attitude before and after the intervention of art DulMuluk (average 56.38 to 59.44, an increase in score of 3.06, $\mathrm{p}=0.05$ ). There is a significant difference in the average score of attitude before and after the 
intervention counseling (average 55.81 to 56.58 , an increase in score of $0.77, \mathrm{p}<0.05$ )

Based on the behavior of pregnant women showed that the majority of pregnant women who carried out the intervention DulMuluk (5 participants) give birth at health professionals, health checks at least 4 times, most exclusively breastfed, one participant did early breastfeeding, and media DulMuluk more attractive and easy to understand.

\section{ACKNOWLEDGMENT}

We would like to thank National Institute of Health Research and Development, Indonesia Health Ministry for providing the research grant.

\section{REFERENCES}

[1] Apriliani, MPEU, et al., "Pagelaran Wayang Cenk Blonk sebagai Media Pendidikan Seks bagi Masyarakat Hindu di Bali.” Jan. 30, 2016. Available: http://http://www.academia.edu, 2012.

[2] Cabrera, A., "Testing The Effectiveness Of An EntertainmentEducation Health-Focused Soap Opera: Exposure and PostDiscussion in Colombian Young Adult". J Investigation \& Desarrollo, 2008. vol. 16 (2).

[3] Depkes RI, "Pesan-pesan tenaga IMD dan ASI untuk tenaga kesehatan dan keluarga Indonesia”. Direktorat Bina Kesehatan Masyarakat Direktorat Gizi Masyarakat. Jakarta, 2008.

[4] DePorter, Bobbi \& Hernacki, Quantum Learning. Bandung: Kaifa, 1999.

[5] Dinkes OI, Profil Kesehatan Ogan Ilir 2013. Dinas Kesehatan Ogan Ilir, 2014

[6] Green, Lawrence W., Health Education Planning, A Diagnostic Approach. California: Mayfield Publishing Company, 1980.

[7] Harvey, B., Stuart, J., \& Swan, T., "Evaluation of a drama-ineducation programme to increase AIDS awareness in South African High Schools: a randomized community intervention trial. "Int $J$ STD AIDS, 11, 2010.

[8] Kelsey, Jennifer, et al., Methods in Observational Epidemiology. New York: Oxford University Press, 1996.

[9] Kursista, IGGN, et al., "The Influence of Innovative Bali Puppet Media In Promoting HIV/AIDS Prevention in The District of Bangli." Berita Kedokteran Masyarakat, vol. 25(4). Jan. 30, 2016 Available:.http://jurnal.ugm.ac.id/bkm/article/view/3555/3044.

[10] Mbizvo, E. Essay: "Theatre-a force for health promotion." The Lancet 2006, 368, S30-S31. Jan. 30, 2016. Available: http: //www.proquest.com

[11] Sasmito, L, et al., "Tari Memengan sebagai Media Penyampaian Posyandu pada Ibu dan Anak di Banyuwangi Jawa Timur". Laporan Akhir Riset Operasional Intervensi Seri Kesehatan Ibu dan Anak Berbasis Budaya Lokal 2012. Jan. 30, 2016. Available: http:ws.ub.ac.id/selma2010/public/images/.../20140424111353_7819 .pdf.

[12] WHO, "Making Pregnancy Safer: The Critical Role of the Skilled Attendant". A Joint Statement of WHO, ICM, and FIGO, 2004. 